\title{
Audit of Women Attending the Aberdeen Genetic Clinic with a Family History of Breast Cancer who Subsequently Develop Cancer
}

\author{
Helen Gregory, Barbara Gibbons \\ and Neva Haites \\ Department of Medical Genetics, Medical \\ School, Foresterhill, Aberdeen AB25 2ZD, \\ $U K$
}

\section{INTRODUCTION}

Breast cancer is a common disease. Improved awareness in the general population of the role of genetic factors in the development of disease has resulted in increasing demands upon Genetic services, and consequently further burden on resources for mammographic screening. Inevitably, some of those women who receive breast screening because of their genetic risk will go on to develop breast cancer themselves. We looked at the population of women who had attended the Aberdeen Genetic Clinic because of their family history to determine those who subsequently developed disease.

\section{METHOD}

1837 women have been seen at the Aberdeen Genetic Clinic between January 1992 and January 1999, for assessment of their family histories of breast cancer. Risks for these individuals were estimated using Houlston data [1] to December 1997 and thereafter Claus data [2]. Of these, 583 women between the ages of 35 and 50 years, and 404 women over the age of 50 years received screening mammography because of their family history.

Extra mammographic surveillance was offered to those whose risk was estimated at more than twice the population average (i.e. greater than $16 \%)$. Those under 50 years of age were offered 2 yearly mammography from age 35 years. Those over 50 years of age were offered 18 monthly mammography to fit in with the NHS National Breast Screening Programme which offers 3 yearly mammography to all women between 50 and 64 years. Mammograms from both groups were assessed by the same team of radiologists.

Pathology registers were checked to ascertain those women who were at high genetic risk who had subsequently developed breast cancer. The expected rates of cancer for the two age groups were then estimated from Scottish cancer statistics [3].

\section{RESULTS}

17 women who have attended the Aberdeen Genetic Clinic with a high-risk family history of breast or ovarian cancer have subsequently developed breast cancer. Of these, 6 were under the age of 50 years and 11 over 50 years (see Table 1). Amongst the younger group, 3 were detected as a result of an abnormal screening mammogram (one of which was a first screening event) and 3 were interval cancers (although one of these was detected at annual clinical examination). In the over 50 group, 9 were 
Table 1

Presentation of cancers

\begin{tabular}{lcc}
\hline & Under 50 years & Over 50 years \\
\hline Screen detected cancers (by mammography) & 3 & 9 \\
Interval cancers & 3 & 2 \\
Total & 6 & 11 \\
\hline
\end{tabular}

Table 2

Observed vs. expected cancers

\begin{tabular}{lcc}
\hline & Under 50 years & Over 50 years \\
\hline Observed cancers & 6 & 11 \\
Expected cancers & 5.95 & 6.30 \\
Chi squared & $\mathrm{p}=>0.5$ & $\mathrm{p}=<0.1$ \\
\hline
\end{tabular}

Table 3

Characteristics of breast cancers diagnosed during screening

\begin{tabular}{|c|c|c|c|c|c|}
\hline Patient & Age & Presentation & Cancer type & Mutation & Comments \\
\hline 1 & 39 & Interval & $\begin{array}{l}\text { Invasive ductal grade } 3+\text { high } \\
\text { grade DCIS }\end{array}$ & No & $\begin{array}{l}\text { Detected by GP on annual } \\
\text { examination. }\end{array}$ \\
\hline 2 & 43 & Screen detected & Invasive tubular grade $2+$ DCIS & No & \\
\hline 3 & 44 & Screen detected & Lobular grade 3 & No & \\
\hline 4 & 45 & $\begin{array}{l}\text { Detected at first } \\
\text { screen }\end{array}$ & DCIS & No & $\begin{array}{l}\text { Tubulovillous adenoma at } \\
\text { colonic screening. }\end{array}$ \\
\hline 5 & 47 & Interval & Invasive ductal grade 3 & $185 \mathrm{del} A G$ & Died 21 months post diagnosis. \\
\hline 6 & 48 & Interval & DCIS & No & $\begin{array}{l}\text { Invasive tubular found in } \\
\text { contralat. breast at prophylactic } \\
\text { mastectomy. }\end{array}$ \\
\hline 7 & 51 & Interval & Invasive ductal grade $2+$ DCIS & No & $\begin{array}{l}\text { DCIS found in contralat. breast } \\
\text { at prophylactic mastectomy. }\end{array}$ \\
\hline 8 & 53 & Screen detected & High grade DCIS & No & \\
\hline 9 & 56 & Screen detected & Invasive ductal grade $3+$ DCIS & No & \\
\hline 10 & 56 & Screen detected & DCIS (widespread) & No & \\
\hline 11 & 57 & Screen detected & Invasive ductal grade 2 & No & \\
\hline 12 & 57 & Screen detected & Invasive ductal grade 2 & No & \\
\hline 13 & 59 & Screen detected & Invasive lobular grade 2 & No & \\
\hline 14 & 61 & Interval & $\begin{array}{l}\text { Cancer of no special type } \\
\text { grade } 2-3\end{array}$ & No & \\
\hline 15 & 64 & Screen detected & Invasive lobular & No & \\
\hline 16 & 64 & Screen detected & Invasive ductal grade 3 & No & \\
\hline 17 & 70 & Screen detected & $\begin{array}{l}\text { Invasive ductal grade } 3+\text { high } \\
\text { grade DCIS }\end{array}$ & No & \\
\hline
\end{tabular}


detected as a result of an abnormal mammogram and only 2 were interval cancers. Three further individuals who had been seen at the Genetic Clinic because of their family history of breast cancer, but whose risk was estimated at below $16 \%$ prior to their diagnoses of breast cancer, were excluded from this study. Of these, two were under 50 years of age and the third was over 50 years. However, the diagnoses of breast cancer in these women have increased the risks of breast cancer for their first-degree relatives to above $16 \%$.

Expected rates of cancer (Cancer Registration Statistics, Scotland) over a period of 6 years for the respective screening groups would be 5.25 cancers in the under 50 group and 6.30 in the over 50's (see Table 2). Using the Chi-Squared test, the difference between observed and affected in the over 50 year group approached significance.

\section{DISCUSSION}

Screening mammography appears to be more effective in the older age group, probably reflecting the decreasing density of breast with age and also the aggressiveness of breast cancers in younger women. Risk analysis appears to be more helpful in predicting genetic cancers in this group, with nearly twice as many cancers occurring as expected from population risks.

However, analysis of risk in the under 50 years group did not help to detect more cancers than expected. This may be due to the availability of prophylactic mastectomy for women at high risk (i.e. women who have inherited or are at 50\% risk of having inherited a breast cancer predisposing gene). To date, 8 women under 50 years of age have proceeded to prophylactic mastectomy in Aberdeen because of their risk, and therefore it is thought that their lifetime risk of developing breast cancer has been significantly reduced [4]. However, no women in the over 50 years group have yet opted for prophylactic mastectomy.

This data will be included in the European multicentre study to assess the outcomes of cancer detected in high-risk women who are receiving extra surveillance. Further assessment of the sensitivity and specificity of genetic risk assessment is required.

\section{Acknowledgements}

We would like to thank the Cytology Laboratory, Department of Pathology, Aberdeen Royal Infirmary, Grampian University Hospitals NHS Trust, for access to their registers.

\section{References}

[1] Houlston, R.S., McCarter, E., Parbhoo, S., Scurr, J.H. and Slack, J. Family history and risk of breast cancer. J. Med. Genet. 29, (1992) 154157.

[2] Claus, E.B., Risch, N. and Thompson, W.D. Genetic analysis of breast cancer in the cancer and steroid hormone study. Am. J. Hum. Genet. 48, (1991) 232-242.

[3] Scottish Cancer Intelligence Unit, Cancer Registration Statistics Scotland 1986-1995. pp. 92-95.

[4] Hartman, L.C., Schaid, D.J., Woods, J.E., Crotty, T.P., Myers, J.L., Arnold, P.G., Petty, P.M., Sellers, T.A., Johnson, J.L., McDonnell, S.K., Frost, M.H. and Jenkins, R.B. Efficacy of bilateral prophylactic mastectomy in women with a family history of breast cancer. NEJM 340, (1999) 77-84. 


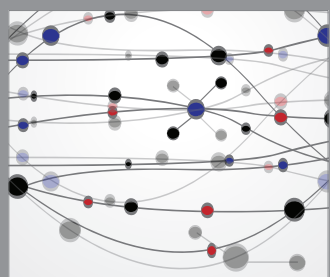

The Scientific World Journal
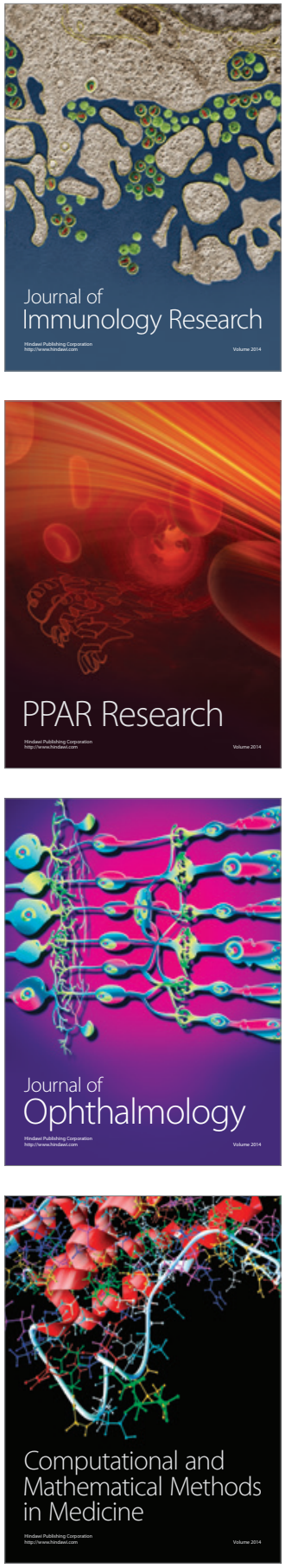

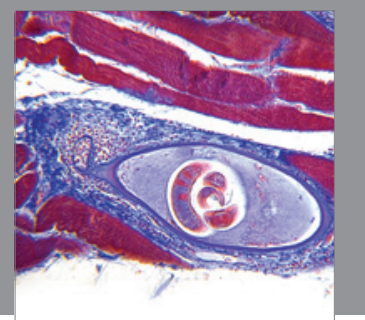

Gastroenterology

Research and Practice
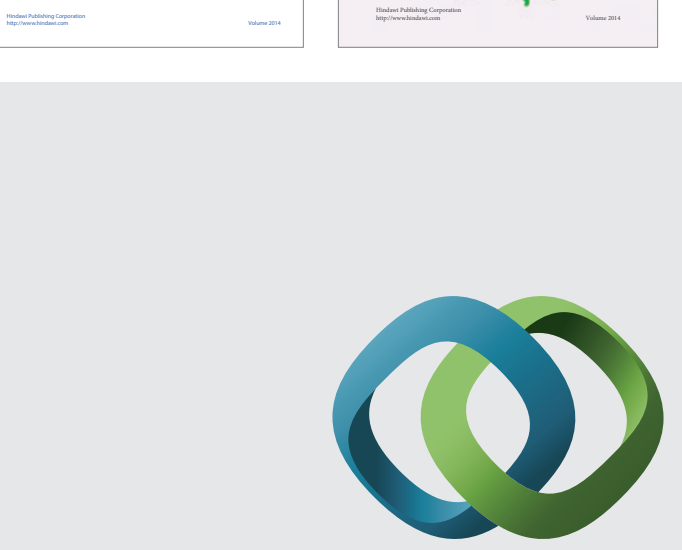

\section{Hindawi}

Submit your manuscripts at

http://www.hindawi.com
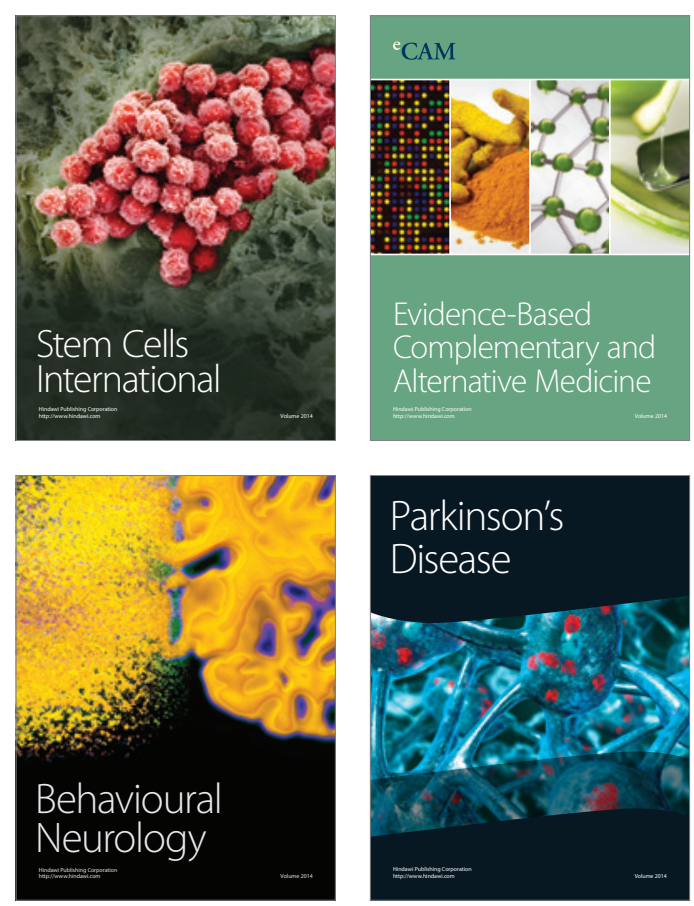

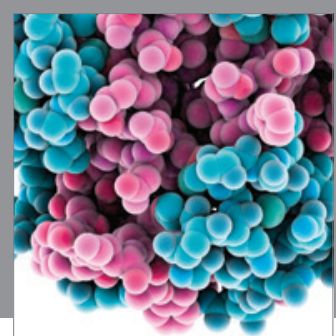

Journal of
Diabetes Research

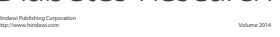

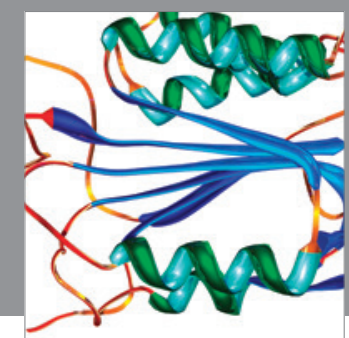

Disease Markers
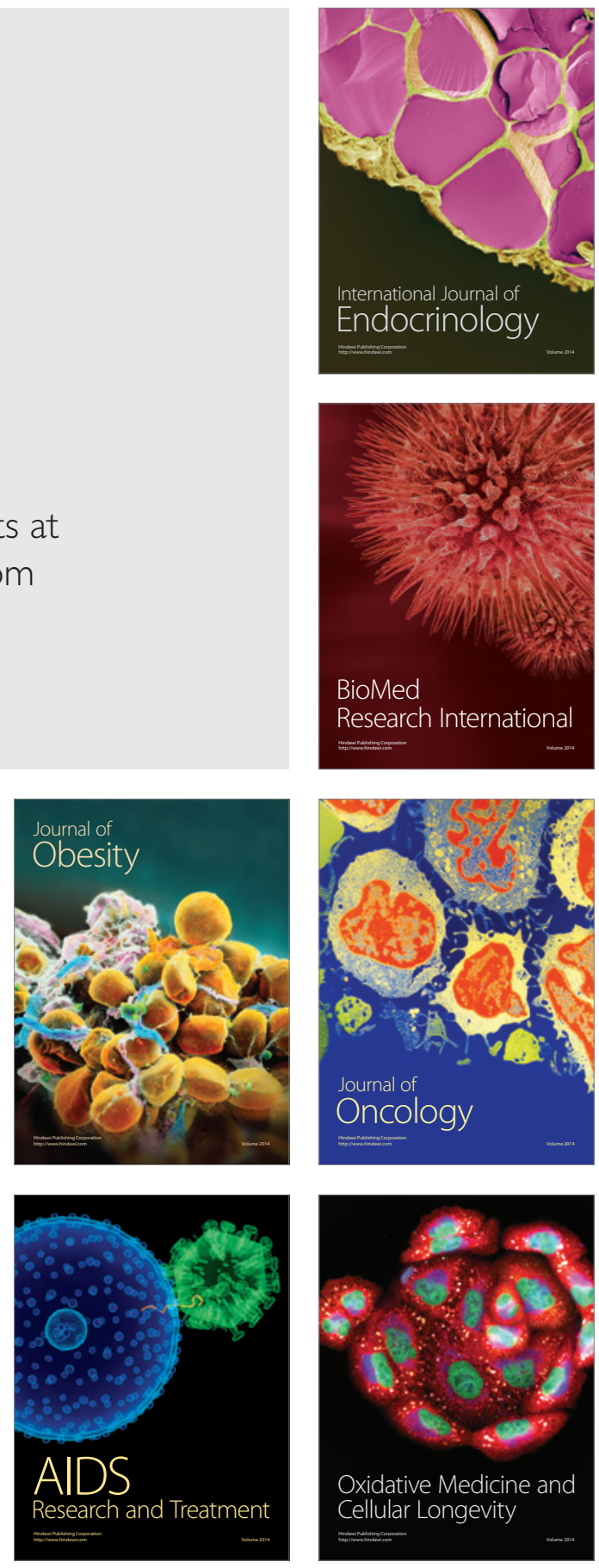